\title{
Utility of Forward-View Echoendoscopy for Transcolonic Fine- Needle Aspiration of Extracolonic Lesions: An Institutional Experience
}

\author{
Nithi Thinrungroj ${ }^{1}{ }^{2}$, Kazuo Hara ${ }^{1}$, Nobumasa Mizuno ${ }^{1}$, Takamichi Kuwahara ${ }^{1}$ and Nozomi Okuno ${ }^{1}$ \\ ${ }^{1}$ Department of Gastroenterology, Aichi Cancer Center Hospital, Nagoya, Japan, ${ }^{2}$ Department of Internal Medicine, Faculty of Medicine, \\ Chiang Mai University, Chiang Mai, Thailand
}

Background/Aims: Non-invasive tissue sampling from the lower intra-abdominal and pelvic cavity is challenging. The role of endoscopic ultrasound-guided fine-needle aspiration (EUS-FNA) in this situation is not well-established because of the limitations of the curved linear-array echoendoscopy-EUS for colonic insertion. The aim of this study was to report our institutional experience of transcolonic EUS-FNA using forward-viewing therapeutic linear echoendoscopy-EUS (FV-EUS) in combination with fluoroscopic guidance.

Methods: Medical records of 13 patients who underwent transcolonic EUS-FNA of extracolonic lesions using FV-EUS in combination with fluoroscopic guidance at Aichi Cancer Center Hospital, Nagoya, Japan from June 2015 to November 2018 were retrospectively reviewed.

Results: Using FV-EUS under fluoroscopic guidance, the FNA procedure could be performed successfully in all patients (100\% technical success), with a median procedure time of 31 minutes. The sensitivity, specificity, and accuracy of EUS-FNA for detecting malignant lesions in this study were $91 \%, 100 \%$, and $92 \%$, respectively. There were no adverse events associated with the EUS-FNA procedure.

Conclusions: FV-EUS in combination with fluoroscopic guidance is an easy, safe, and effective technique for FNA of extracolonic lesions in the lower abdomen. Clin Endosc 2020;53:60-64

Key Words: Endoscopic ultrasound-guided fine-needle aspiration; Forward-viewing echoendoscope; Non-invasive tissue sampling; Recurrent colorectal cancer; Transcolonic fine-needle aspiration

\section{INTRODUCTION}

Endoscopic ultrasound-guided fine-needle aspiration (EUSFNA) has become a standard method for the pathological diagnosis of upper abdominal lesions, such as pancreatic tumors, gastrointestinal submucosal tumors, or the lymph

\footnotetext{
Received: April 9,2019 Revised: June 4, 2019

Accepted: July 1, 2019

Correspondence: Kazuo Hara

Department of Gastroenterology, Aichi Cancer Center Hospital, 1-1 Kanokoden,

Chikusa-ku, Nagoya 464-8681, Japan

Tel: +81-52-762-6111, Fax: +81-52-764-2963, E-mail: Khara@aichi-cc.jp

ORCID: https://orcid.org/0000-0002-4699-6136
}

(cc) This is an Open Access article distributed under the terms of the Creative Commons Attribution Non-Commercial License (http://creativecommons.org/ licenses/by-nc/3.0) which permits unrestricted non-commercial use, distribution, and reproduction in any medium, provided the original work is properly cited. nodes. $^{1-6}$

The usefulness of EUS-FNA for lower abdominal lesions is questionable, with only a few supporting evidence-based studies. Recently, the use of EUS-FNA for the lower abdomen has gained popularity with the use of curved linear-array echoendoscopy-EUS (CLA-EUS). ${ }^{7-12}$ Most trials puncture mainly in the rectal and perirectal area because of the technical difficulty and risk of perforation for deeper insertion. However, proximal colonic insertion can be easily performed, such as conventional colonoscopy using forward-viewing therapeutic linear echoendoscopy-EUS (FV-EUS), which combines the front endoscopic and ultrasonographic views. However, FNA of extracolonic lesions is still a technical challenge.

In this study, we report our experience with transcolonic EUS-FNA for extracolonic lesions in the lower abdominopelvic cavity using FV-EUS under fluoroscopic guidance. 


\section{MATERIAL AND METHODS}

\section{Patients}

A retrospective review of 13 consecutive patients who underwent transcolonic EUS-FNA with FV-EUS under fluoroscopic guidance at the Aichi Cancer Center Hospital, Nagoya, Japan from June 2015 to November 2018 was conducted. All patient had an intra-abdominopelvic mass or abnormal lymph

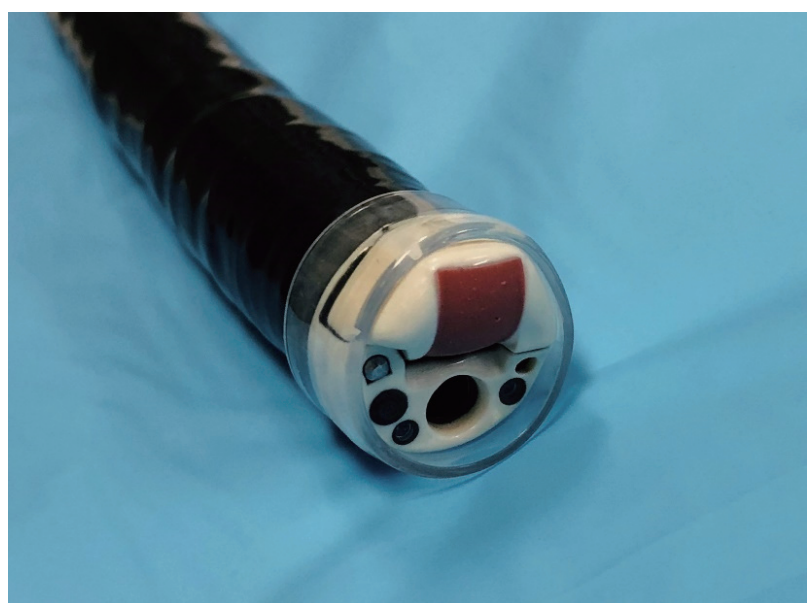

Fig. 1. Forward-view echoendoscope (TGF-UC260J; Olympus Medical Systems, Tokyo, Japan) with a transparent cap. node detected on cross-sectional imaging, such as abdominopelvic computed tomography (CT), magnetic resonance imaging (MRI), or positron emission tomography/CT (PET/ CT). All patients provided informed consent for EUS-FNA. The study protocol was approved by the Institutional Review Board (IRB No. 2018-1-223 date 5/Nov/2018).

\section{EUS-FNA technique}

A forward-view echoendoscope (TGF-UC260J; Olympus Medical Systems, Tokyo, Japan) was used for all patients. Compared to CLA-EUS, FV-EUS has unique advantages, such as of a straight channel port, wider bending angulation, and shorter distal end (Fig. 1) These features provide greater puncture force and ability to access the proximal colon. The disadvantage of FV-EUS is a narrower ultrasonographic scanning range $\left(90^{\circ}\right)$ compared to that of the CLA-EUS $\left(180^{\circ}\right)$. We added an extra monitor for the cross-sectional imaging in addition to the fluoroscopic monitor to compare the scope position relative to the target lesion.

The procedure was performed under conscious sedation with intravenous administration of midazolam and pethidine. First, the patient was placed in the left lateral position. The FV-EUS scope was inserted under the endoscopic view into the colonic segment near the target FNA lesion. A C-arm $\mathrm{X}$-ray machine was used to change the plane of the X-ray and
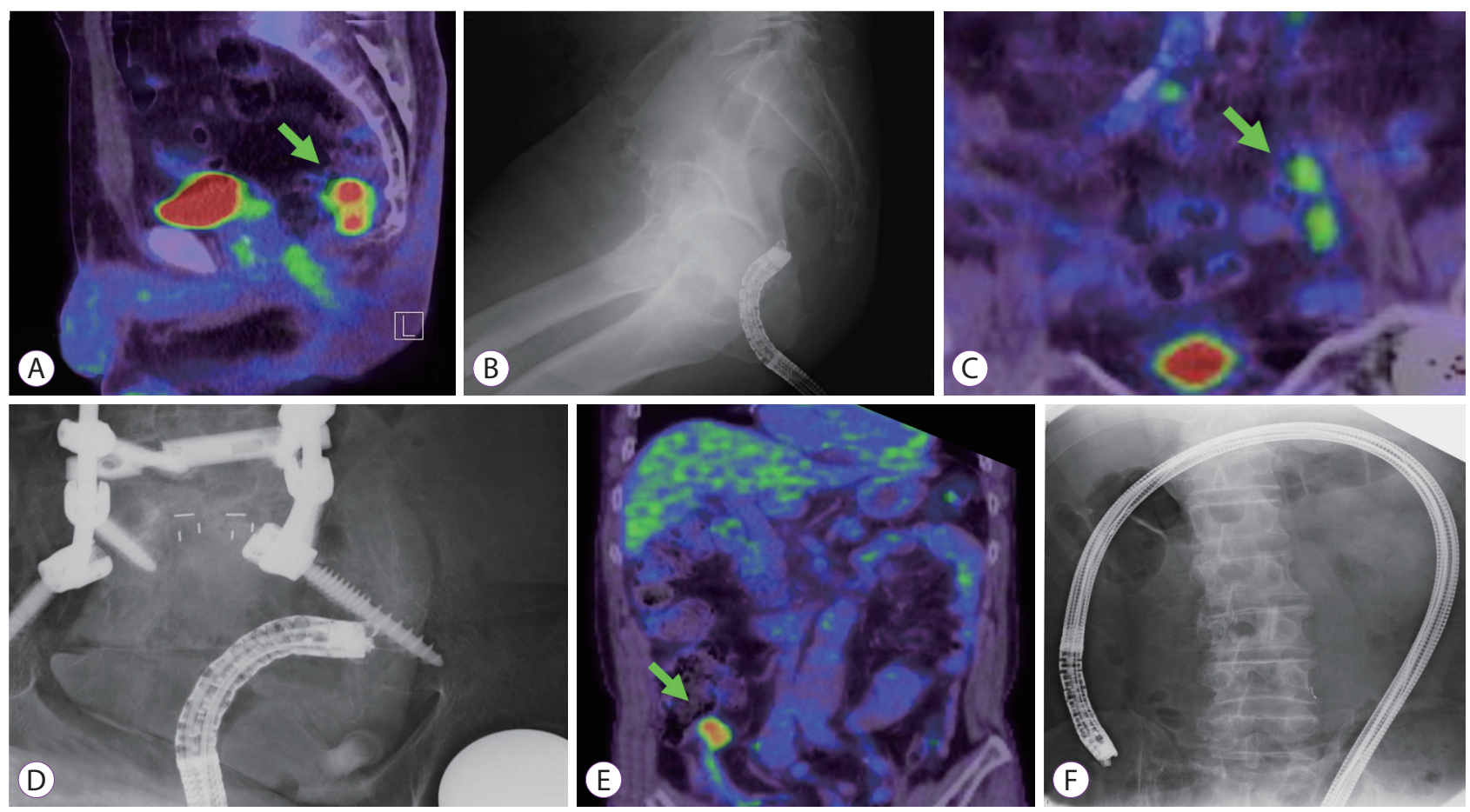

Fig. 2. The target lesion (green arrow) on positron emission tomography/computed tomography (PET/CT) (A), and the scope tip position on fluoroscopy (B) in patient 9. The target lesion (green arrow) on PET/CT (C), and the scope tip position on fluoroscopy (D) in patient 11. The target lesion (green arrow) on PET/CT (E), and the scope tip position on fluoroscopy $(\mathrm{F})$ in patient 13 . 
compare the scope tip position on fluoroscopy to the target FNA lesion on cross-sectional imaging, such as CT, MRI, or PET/CT (Fig. 2). Next, the target lesion was searched under the ultrasonographic view. When the target lesion was found, fluoroscopy was used to confirm that the position and direction of the scope was correct and close to the target lesion, as on cross-sectional imaging (Fig. 2).

FNA was performed with a 22- or 25-gauge needle. After each puncture, specimens were sent for rapid onsite evaluation (ROSE), cytology, and/or tissue cell block. FNA was repeated, varying from one to six times, depending on the ROSE result. All procedures were performed in the fluoroscopic room by four experienced endosonographers at our center.

\section{Outcomes}

The primary outcome of this study was the diagnostic ability of EUS-FNA. The diagnosis was made using cytology and/ or cell block. The outcome was evaluated based on sensitivity, specificity, and accuracy for the diagnosis. Table 1 presents the other outcomes, including location and size of the lesion, puncture site, provisional diagnosis, procedure time, cytological outcome, final diagnosis, and adverse events.

\section{RESULTS}

From June 2015 to November 2018, EUS-FNA was performed at our center with FV-EUS under fluoroscopic guidance for 13 patients with extracolonic lesions. The sensitivity, specificity, and accuracy of EUS-FNA for detecting malignant lesions in this study were $91 \%, 100 \%$, and $92 \%$, respectively. There was only one false-negative case, which was of a chemotherapy patient after rectal cancer surgery. Table 1 summarizes the clinical, radiological, and procedural data.

Most patients (69\%) had undergone surgery for colorectal cancer with suspected recurrence on follow-up imaging

Table 1. Clinical, Radiological, and Procedural Data

\begin{tabular}{|c|c|c|c|c|c|c|c|c|c|}
\hline Patient & Target lesion & $\begin{array}{l}\text { Size } \\
(\mathrm{mm})\end{array}$ & Imaging & $\begin{array}{c}\text { Provisional } \\
\text { diagnosis }\end{array}$ & Site of FNA & $\begin{array}{l}\text { Procedure } \\
\text { time (min) }\end{array}$ & $\begin{array}{l}\text { Cytology and/or } \\
\text { cell block }\end{array}$ & Final diagnosis & $\begin{array}{c}\text { Adverse } \\
\text { event }\end{array}$ \\
\hline 1 & $\begin{array}{l}\text { Pelvic cavity } \\
\text { LN }\end{array}$ & 18 & $\mathrm{PET} / \mathrm{CT}$ & $\begin{array}{l}\text { Recurrent rectal } \\
\text { cancer }\end{array}$ & $\begin{array}{l}\text { Sigmoid } \\
\text { colon }\end{array}$ & 50 & No malignancy & $\begin{array}{l}\text { Recurrent rectal } \\
\text { cancer }\end{array}$ & No \\
\hline 2 & $\begin{array}{l}\text { Appendiceal } \\
\text { mass }\end{array}$ & 33.5 & $\mathrm{PET} / \mathrm{CT}$ & $\begin{array}{l}\text { Appendiceal } \\
\text { Tumor }\end{array}$ & $\begin{array}{l}\text { Sigmoid } \\
\text { colon }\end{array}$ & 48 & Granulation tissue & $\begin{array}{r}\text { Mass forming } \\
\text { appendicitis }\end{array}$ & No \\
\hline 3 & $\begin{array}{l}\text { Pelvic cavity } \\
\text { mass }\end{array}$ & 43 & $\mathrm{PET} / \mathrm{CT}$ & $\begin{array}{l}\text { Recurrent rectal } \\
\text { cancer }\end{array}$ & Rectum & 44 & Adenocarcinoma & $\begin{array}{l}\text { Recurrent rectal } \\
\text { cancer }\end{array}$ & No \\
\hline 4 & $\begin{array}{l}\text { peritoneal } \\
\text { mass }\end{array}$ & 28 & $\mathrm{PET} / \mathrm{CT}$ & Metastatic CCA & Rectum & 31 & Adenocarcinoma & $\begin{array}{l}\text { CCA, peritoneal } \\
\text { metastasis }\end{array}$ & No \\
\hline 5 & $\begin{array}{l}\text { Pelvic cavity } \\
\text { LN }\end{array}$ & 12.2 & $\mathrm{PET} / \mathrm{CT}$ & $\begin{array}{l}\text { Recurrent colon } \\
\text { cancer }\end{array}$ & Rectum & 46 & Adenocarcinoma & $\begin{array}{l}\text { Recurrent colon } \\
\text { cancer }\end{array}$ & No \\
\hline 6 & $\begin{array}{l}\text { Pelvic cavity } \\
\text { LN }\end{array}$ & 15 & $\mathrm{PET} / \mathrm{CT}$ & $\begin{array}{l}\text { Metastatic } \\
\text { gastric cancer }\end{array}$ & Rectum & 20 & Adenocarcinoma & $\begin{array}{l}\text { Recurrent gastric } \\
\text { cancer }\end{array}$ & No \\
\hline 7 & $\begin{array}{l}\text { Pelvic cavity } \\
\text { mass }\end{array}$ & 40 & CT & $\begin{array}{l}\text { Recurrent ovar- } \\
\text { ian cancer }\end{array}$ & $\begin{array}{l}\text { Sigmoid } \\
\text { colon }\end{array}$ & 21 & Adenocarcinoma & $\begin{array}{l}\text { Ovarian cancer, } \\
\text { peritoneal } \\
\text { metastasis }\end{array}$ & No \\
\hline 8 & Pelvic nodule & 40 & $\mathrm{PET} / \mathrm{CT}$ & $\begin{array}{l}\text { Recurrent rectal } \\
\text { cancer }\end{array}$ & Rectum & 19 & Adenocarcinoma & $\begin{array}{l}\text { Recurrent rectal } \\
\text { cancer }\end{array}$ & No \\
\hline 9 & $\begin{array}{c}\text { Retroperito- } \\
\text { neal mass }\end{array}$ & 18 & $\mathrm{PET} / \mathrm{CT}$ & $\begin{array}{l}\text { Recurrent colon } \\
\text { cancer }\end{array}$ & $\begin{array}{l}\text { Sigmoid } \\
\text { colon }\end{array}$ & 48 & Adenocarcinoma & $\begin{array}{l}\text { Recurrent colon } \\
\text { cancer }\end{array}$ & No \\
\hline 10 & $\begin{array}{l}\text { Pelvic cavity } \\
\text { LN }\end{array}$ & 20 & CT & $\begin{array}{l}\text { Recurrent rectal } \\
\text { cancer }\end{array}$ & $\begin{array}{l}\text { Sigmoid } \\
\text { colon }\end{array}$ & 28 & No malignancy & Benign LN & No \\
\hline 11 & $\begin{array}{l}\text { Pelvic cavity } \\
\text { LN }\end{array}$ & 19.3 & $\mathrm{PET} / \mathrm{CT}$ & $\begin{array}{l}\text { Recurrent colon } \\
\text { cancer }\end{array}$ & $\begin{array}{l}\text { Descending } \\
\text { colon }\end{array}$ & 31 & Adenocarcinoma & $\begin{array}{l}\text { Recurrent colon } \\
\text { cancer }\end{array}$ & No \\
\hline 12 & $\begin{array}{l}\text { Retroperito- } \\
\text { neal LN }\end{array}$ & 17.8 & $\mathrm{PET} / \mathrm{CT}$ & $\begin{array}{l}\text { Recurrent rectal } \\
\text { cancer }\end{array}$ & $\begin{array}{l}\text { Sigmoid } \\
\text { colon }\end{array}$ & 13 & Adenocarcinoma & $\begin{array}{l}\text { Recurrent rectal } \\
\text { cancer }\end{array}$ & No \\
\hline 13 & $\begin{array}{c}\text { Pericecal } \\
\text { nodule }\end{array}$ & 20 & $\mathrm{PET} / \mathrm{CT}$ & $\begin{array}{l}\text { Recurrent rectal } \\
\text { cancer }\end{array}$ & Cecum & 34 & Adenocarcinoma & $\begin{array}{l}\text { Recurrent rectal } \\
\text { cancer }\end{array}$ & No \\
\hline
\end{tabular}

CCA, cholangiocarcinoma; CT, computed tomography; FNA, fine-needle aspiration; LN, lymph node; PET, positron emission tomography. 
(typically CT, MRI, or PET/CT) and showed an intraabdominal lymph node or mass. The median diameter of the target FNA lesion was $20 \mathrm{~mm}$, with an interquartile range (IQR) of $18-33.5 \mathrm{~mm}$, and the most common puncture location was the lower intra-abdominopelvic cavity by the transigmoid or transrectal FNA. The FNA procedure can be performed successfully in patients (100\% technical success) with a median procedural time of $31 \mathrm{~min}$ with an IQR of 21-46 min. There were no adverse events associated with the EUS-FNA procedure.

\section{DISCUSSION}

Recent studies showed that CLA-EUS is effective and safe for FNA of perirectal lesions. ${ }^{12-14}$ However, for proximal pericolonic lesions, CLA-EUS seems to be technically difficult in scope insertion and increases the risk of perforation. To our knowledge, there is only one study that used CLA-EUS for FNA. In that study by Sasaki et al., ${ }^{15}$ FNA was performed for the colonic submucosal mass and extrinsic masses abutting to the wall of the colon proximal to the sigmoid colon in four patients, using CLA-EUS together with the overtube and guidewire. First, they used a colonoscope to insert the overtube and guidewire, and subsequently, inserted the CLA-EUS scope into the overtube under the guidewire. However, this technique is complicated, time-consuming, and requires many instruments.

To overcome these limitations, our institution used FV-EUS in combination with fluoroscopic guidance as the first-line technique to perform FNA for intra-abdominal and pelvic cavity lesions. The FV-EUS scope can be easily navigated and inserted into the proximal colon like a conventional colonoscope. To our knowledge, there are only two published studies using FV-EUS for FNA of the pericolonic lesion; however, neither study used fluoroscopy. In the first study, by Nguyen-Tang et al..$^{16}$ in 2010, FV-EUS was performed to evaluate and obtain samples of the right-sided colonic subepithelial lesions in 15 patients. With FV-EUS, they could reach the cecum within 10 minutes in every case. This study confirmed that FV-EUS can provide easy and safe insertion into the proximal colon. However, all target lesions in this study were subepithelial lesions that could be found under the conventional endoscopic view. The second study, by Uchida et al. ${ }^{17}$ in 2010, reported using FV-EUS for FNA of extracolonic lesions in two patients. The target lesions were $30 \mathrm{~mm}$ of the common iliac lymph node abutting to the ascending colon and a $7-\mathrm{cm}$ mass surrounding the descending colon. These two studies suggested that FV-EUS is effective and safe for FNA of proximal pericolonic lesions.
However, while using FV-EUS without fluoroscopy, it is difficult to find the target lesion under the ultrasonographic view alone because the scanning range of the FV-EUS $\left(90^{\circ}\right)$ is narrower than that of the CLA-EUS $\left(180^{\circ}\right)$. In addition, there is no standard homebase structure in the proximal colon. Therefore, without fluoroscopic guidance, FNA would be suitable for subepithelial lesions (visible in the endoscopic view) or big lesions that are easily seen under the ultrasound view, as in previous studies. However, FNA of small extracolonic lesions are still challenging with FV-EUS. Our center uses fluoroscopy to aid FV-EUS in finding the target lesion by positioning the tip of the scope as close as possible to the target lesion on cross-sectional imaging before scanning and puncture (Fig. 2). In our results, the target lesions were small, with a median diameter of $20 \mathrm{~mm}$ (IQR, $17.2 \mathrm{~mm}$ ), and the median procedure time was $31 \mathrm{~min}$ (IQR, $26 \mathrm{~min}$ ). We believe that this technique can facilitate in locating the target lesions (even small extracolonic lesions) on ultrasound. Moreover, tissue sampling for histopathologic examination was technically successful in all patients, with a sensitivity of $91 \%$ and specificity of $100 \%$, which allowed to differentiate between neoplastic and non-neoplastic lesions without any post-procedural adverse events. These outcomes showed that the effectiveness and safety of this technique were acceptable and comparable to those of standard EUS-FNA.

In our study, most lesions were located in the lower abdominopelvic cavity on EUS-FNA in the distal colon, while five and six were in the rectum and sigmoid colon, respectively. Only two cases were punctured more proximal in the distal descending colon and cecum. The lesion in the upper abdominal cavity can be punctured using transoral EUS-FNA or ultrasound-guided percutaneous biopsy without difficulty. Transcolonic EUS-FNA is best indicated for FNA of lesions in the lower abdominopelvic cavity by puncturing through rectum, sigmoid, and distal descending colon because the lesion in this area is surrounded by pelvic bones and major organs, such as the urinary bladder and uterus, which make the percutaneous approach difficult. We also used FV-EUS as the first-line technique for FNA of perirectal lesions (5 cases). Our endoscopists reported that compared to the experience with CLA-EUS, FV-EUS with a short scope tip was easier for scope manipulation and puncture, especially for the lesions in the lower rectum with limited space. Moreover, EUS-FNA with FV-EUS under fluoroscopy does not require expertise in EUS, so this technique may be more helpful, particularly in centers where an expert endosonographer is not available.

Our study had several limitations. First, our study had a retrospective design in a single center with a few cases. Second, although this study reported using FV-EUS of proximal pericolonic lesions, all cases except one were of left-sided peri- 
colonic lesions. Large prospective cohort studies are required to validate the findings of this study.

In conclusion, diagnosing lower intra-abdominopelvic lesions is still challenging. However, FV-EUS under fluoroscopic guidance is an easy, safe, and effective technique for transcolonic EUS-FNA of lesions in the abdominopelvic cavity.

\section{Conflicts of Interest}

The authors have no financial conflicts of interest.

\section{Author Contributions}

Conceptualization: Nithi Thinrungroj, Kazuo Hara, Nobumasa Mizuno, Takamichi Kuwahara, Nozomi Okuno

Data curation: NT, NM, TK, NO

Formal analysis: NT, NM, TK, NO

Supervision: $\mathrm{KH}, \mathrm{NM}$, TK, NO

Writing-original draft: NT

Writing-review\&editing: $\mathrm{KH}$

\section{REFERENCES}

1. Dumonceau JM, Polkowski M, Larghi A, et al. Indications, results, and clinical impact of endoscopic ultrasound (EUS)-guided sampling in gastroenterology: European Society of Gastrointestinal Endoscopy (ESGE) clinical guideline. Endoscopy 2011;43:897-912.

2. Nishida T, Kawai N, Yamaguchi S, Nishida Y. Submucosal tumors: comprehensive guide for the diagnosis and therapy of gastrointestinal submucosal tumors. Dig Endosc 2013;25:479-489.

3. Yoshinaga S, Suzuki H, Oda I, Saito Y. Role of endoscopic ultrasound-guided fine needle aspiration (EUS-FNA) for diagnosis of solid pancreatic masses. Dig Endosc 2011;23 Suppl 1:29-33.

4. Mohammad Alizadeh AH, Shahrokh S, Hadizadeh M, Padashi M, Zali MR. Diagnostic potency of EUS-guided FNA for the evaluation of pancreatic mass lesions. Endosc Ultrasound 2016;5:30-34.

5. Chen VK, Eloubeidi MA. Endoscopic ultrasound-guided fine needle aspiration is superior to lymph node echofeatures: a prospective evalua- tion of mediastinal and peri-intestinal lymphadenopathy. Am J Gastroenterol 2004;99:628-633.

6. Chin YK, Iglesias-Garcia J, de la Iglesia D, et al. Accuracy of endoscopic ultrasound-guided tissue acquisition in the evaluation of lymph nodes enlargement in the absence of on-site pathologist. World J Gastroenterol 2017;23:5755-5763.

7. Edelman BR, Weiser MR. Endorectal ultrasound: its role in the diagnosis and treatment of rectal cancer. Clin Colon Rectal Surg 2008;21:167177.

8. Hünerbein M, Totkas S, Moesta KT, Ulmer C, Handke T, Schlag PM. The role of transrectal ultrasound-guided biopsy in the postoperative follow-up of patients with rectal cancer. Surgery 2001;129:164-169.

9. Pishvaian AC, Ahlawat SK, Garvin D, Haddad NG. Role of EUS and EUS-guided FNA in the diagnosis of symptomatic rectosigmoid endometriosis. Gastrointest Endosc 2006;63:331-335.

10. Shami VM, Parmar KS, Waxman I. Clinical impact of endoscopic ultrasound and endoscopic ultrasound-guided fine-needle aspiration in the management of rectal carcinoma. Dis Colon Rectum 2004;47:59-65.

11. Sailer M, Bussen D, Fein M, et al. Endoscopic ultrasound-guided transrectal biopsies of pelvic tumors. J Gastrointest Surg 2002;6:342-346.

12. Fernández-Esparrach G, Alberghina N, Subtil JC, et al. Endoscopic ultrasound-guided fine needle aspiration is highly accurate for the diagnosis of perirectal recurrence of colorectal cancer. Dis Colon Rectum 2015;58:469-473.

13. Amin K, Olyaee M, Tawfik O, Fan F. Endoscopic ultrasound-guided fine needle aspiration as a diagnostic and staging tool for rectal and perirectal lesions-an institutional experience. Ann Diagn Pathol 2013;17:494497.

14. Rotondano G, Esposito P, Pellecchia L, Novi A, Romano G. Early detection of locally recurrent rectal cancer by endosonography. Br J Radiol 1997;70:567-571.

15. Sasaki Y, Niwa Y, Hirooka Y, et al. The use of endoscopic ultrasound-guided fine-needle aspiration for investigation of submucosal and extrinsic masses of the colon and rectum. Endoscopy 2005;37:154160.

16. Nguyen-Tang T, Shah JN, Sanchez-Yague A, Binmoeller KF. Use of the front-view forward-array echoendoscope to evaluate right colonic subepithelial lesions. Gastrointest Endosc 2010;72:606-610.

17. Uchida N, Galasso D, Seerden TC, et al. EUS-FNA of extracolonic lesions by using the forward-viewing linear echoendoscope. Gastrointest Endosc 2010;72:1321-1323. 